\title{
Familial pericentric inversion of chromosome 1 (p34q23) and male infertility with stage specific spermatogenic arrest
}

\author{
D Meschede, U G Froster, M Bergmann, E Nieschlag
}

\section{Institute of Reproductive Medicine of the Strasse 107, D-48149 Strasse 107, D-48149
Münster, Germany D Meschede*}

E Nieschlag

Women's Hospital, Ratzeburger Allee 160,

Germany

U G Froster

Institute of Anatomy of the University,

Vesaliusweg 2-4,

D-48139 Münster,

Germany

M Bergmann

* Present address: Institute of Human Genetics of the University, Münster,

Germany.

Correspondence to Professor Nieschlag.

Received 3 November 1993 Revised version accepted for publication 4 March 1994 University of Lübeck, D-23562 Lübeck,

\begin{abstract}
We report on two infertile brothers presenting with severe oligozoospermia or azoospermia. Testicular biopsy was performed on one of them and showed spermatogenic arrest at the level of primary spermatocytes. Both brothers were found to be heterozygous for a pericentric inversion of chromosome 1 $(46, X Y, \operatorname{inv}(1)(p 34 q 23))$. The inversion chromosome was inherited through the maternal line, with no indication of subfertility in the probands' mother.
\end{abstract}

\section{(F Med Genet 1994;31:573-575)}

Chromosomal abnormalities have a higher prevalence among infertile males than in the general population. Numerical and structural aberrations of the sex chromosomes prevail, but structural rearrangements of the autosomes are also found with significantly increased frequency. ${ }^{1}$ Here we report a family with a rare familial pericentric inversion of chromosome 1 (46,XY,inv(1)(p34q23)) and infertility in two brothers.

\section{Family report}

The 30 year old proband (III.2, fig 1) presented with infertility of five years' duration. His wife had undergone a complete gynaecological workup, with no abnormalities detected. Previous examinations of the proband at other hospitals had shown severely impaired sperm counts.

I
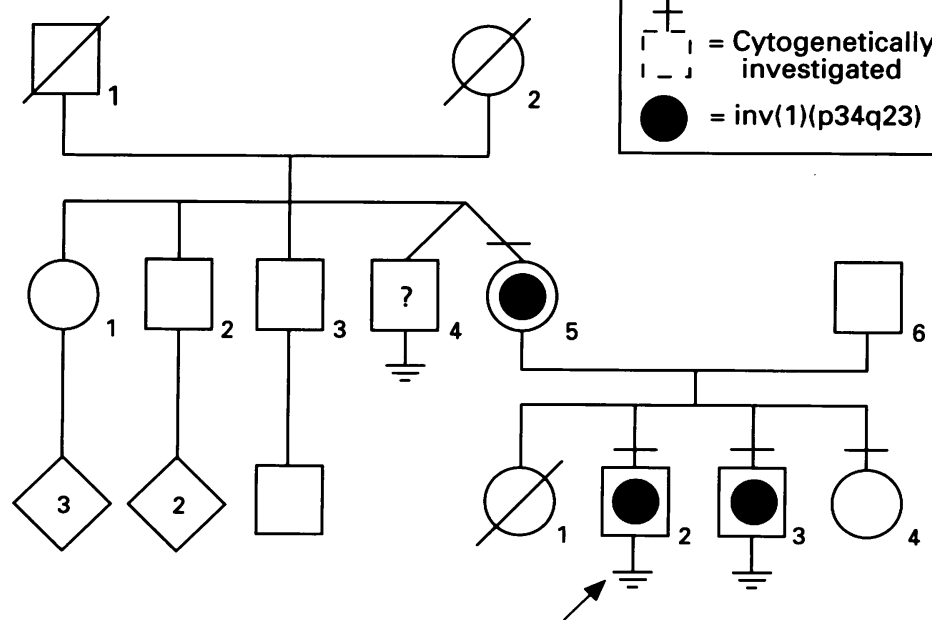

Figure 1 Pedigree of family with large pericentric inversion of chromosome 1. Proband is indicated by arrow.
Genital and general physical examination were unremarkable. The results of semen analyses and endocrine studies are summarised in the table. Testosterone and LH were slightly subnormal on one occasion, but all other hormonal values were within the normal range. Semen analysis showed a normal ejaculate volume and normal concentrations of the marker substances for the prostate (zinc), the seminal vesicles (fructose), and the epididymis $(\alpha$-glucosidase). Sperm concentration was extremely low and on one occasion there was complete azoospermia. Percentages of progressively motile and morphologically normal spermatozoa were reduced. A surgical exploration of the scrotum showed normal epididymides and vas deferentia. A biopsy was taken from both testes. In the majority of tubules spermatogenesis was arrested at the level of primary spermatocytes (fig 2). No tubules with Sertoli cell only histology were seen. Karyotype analysis on peripheral lymphocytes showed heterozygosity for a large pericentric inversion of chromosome $1(46, \mathrm{XY}, \operatorname{inv}(1)$ (pter $\rightarrow$ p34::q23 $\rightarrow$ p34::q23 $\rightarrow$ qter) (fig 3). A permanent cell line is not available.

The marriage of the proband's younger brother (III.3) had remained barren for several years. Semen analysis at another institution had reportedly shown azoospermia. The brother refused physical examination and diagnostic tests other than chromosome studies and basic hormone measurements. Karyotyping showed heterozygosity for the same large inversion of chromosome $1(46, \mathrm{XY}, \operatorname{inv}(1)$ (p34q23)) as in his brother. The proband's sister had a normal female karyotype $(46, \mathrm{XX})$. His mother was found to be heterozygous for the same pericentric inversion of chromosome $1(46, X X, \operatorname{inv}(1)(p 34 q 23))$. She denied pregnancy losses or other reproductive and health problems. Her first child (III-1) had died of a viral infection. Her twin brother's (II-4) marriage had remained barren for unknown reasons. Neither this subject nor any other family members were available for chromosome studies.

\section{Discussion}

Heterozygosity for a pericentric inversion of chromosome 1 has been reported in a small number of infertile male patients. ${ }^{2-8}$ As is true for other balanced autosomal rearrangements, such inversions appear to compromise the fertility of some male, but not female carriers The factors determining this selective suscep- 
Spermatological and endocrine parameters in subject $I I I \cdot 2$

\begin{tabular}{|c|c|c|c|c|c|}
\hline \multirow[b]{2}{*}{ Parameter } & \multicolumn{5}{|c|}{ Sample No } \\
\hline & 1 & 2 & 3 & 4 & Normal range \\
\hline 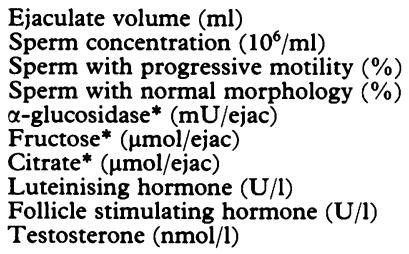 & $\begin{array}{r}4 \cdot 5 \\
0 \cdot 2 \\
40 \\
30 \\
114 \\
88 \\
64 \\
1 \cdot 9 \\
4 \cdot 3 \\
10 \cdot 0\end{array}$ & $\begin{array}{l}4 \cdot 2 \\
0 \\
- \\
- \\
88 \\
69 \\
56 \\
2 \cdot 9 \\
4 \cdot 9 \\
18 \cdot 2\end{array}$ & $\begin{array}{c}3.8 \\
0.05 \\
20 \\
7\end{array}$ & $\begin{array}{c}3.9 \\
0.1 \\
20 \\
8\end{array}$ & $\begin{array}{l}\geqslant 2 \\
\geqslant 20 \\
\geqslant 50 \\
\geqslant 30 \\
\geqslant 11 \\
\geqslant 13 \\
\geqslant 32 \\
2-10 \\
1-7 \\
\geqslant 12\end{array}$ \\
\hline
\end{tabular}

* $\alpha$-glucosidase, fructose, and citrate are marker substances for the epididymis, the semina vesicles, and the prostate, respectively.

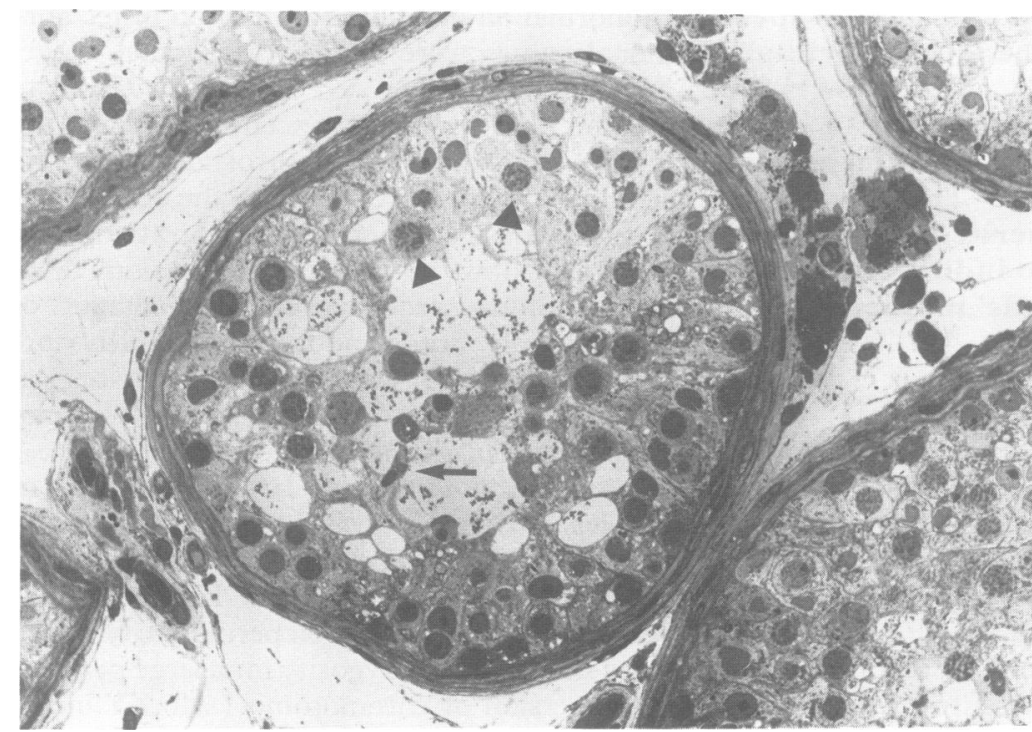

Figure 2 Photomicrograph of seminiferous tubule from case 1, showing arrest of spermatogenesis at the level of primary spermatocytes (arrowheads). Note one single elongated spermatid (arrow). tibility of male gametogenesis are obscure. Formal proof for a causal relationship between the karyotypic abnormality and impaired fertility is difficult to obtain in the individual case. The possibility of coincidence must be kept in mind.

The unusual karyotype in our proband was associated with a specific histopathology, that is, stage specific arrest of spermatogenesis. The maturation arrest at the level of primary spermatocytes indicates a disturbance of meiosis I. In non-obstructive azoospermia (and severe oligozoospermia) serum FSH levels are usually raised, a finding notably absent in our patient. There is evidence that increased levels of FSH depend on the presence of seminiferous tubules with Sertoli cell only (SCO) histology. ${ }^{9}$ If no SCO tubules are found, then FSH may be expected to be normal, even if spermatogenesis is compromised. The endocrine data from our patient are in keeping with these observations.

Only one other patient with a pericentric inversion of chromosome 1 with the same breakpoints ( $\mathrm{p} 34 \mathrm{q} 23$ ) has been reported so far. ${ }^{8}$ In this and the other published cases of male infertility associated with a pericentric inversion of chromosome 1 (but with different breakpoints involved $)^{2-7}$ the clinical data provided are often scanty and thus difficult to interpret. No clear relationship between the specific chromosomal breakpoints and degree of spermatogenic failure emerges. The fact that several male carriers of pericentric chromosome 1 inversions were ascertained in amniocentesis series $^{10}$ indicates that this karyotypic abnormality is not invariably associated with infertility.

To enhance our understanding of the relationship between pericentric autosomal inver-
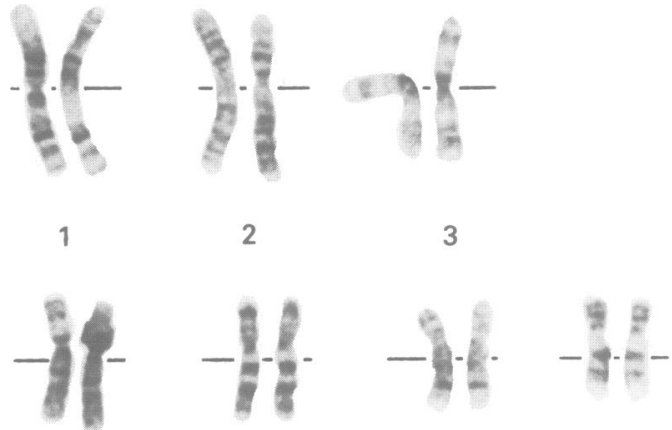

6

7
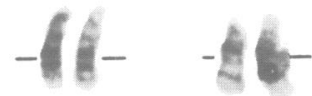

14

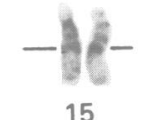

15
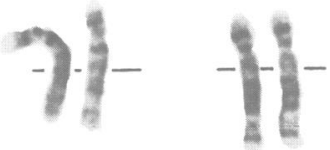

4
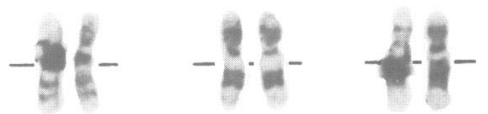

10

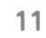

12
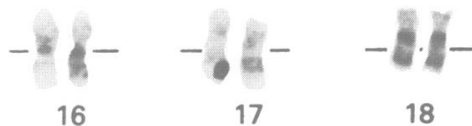

16

17

18
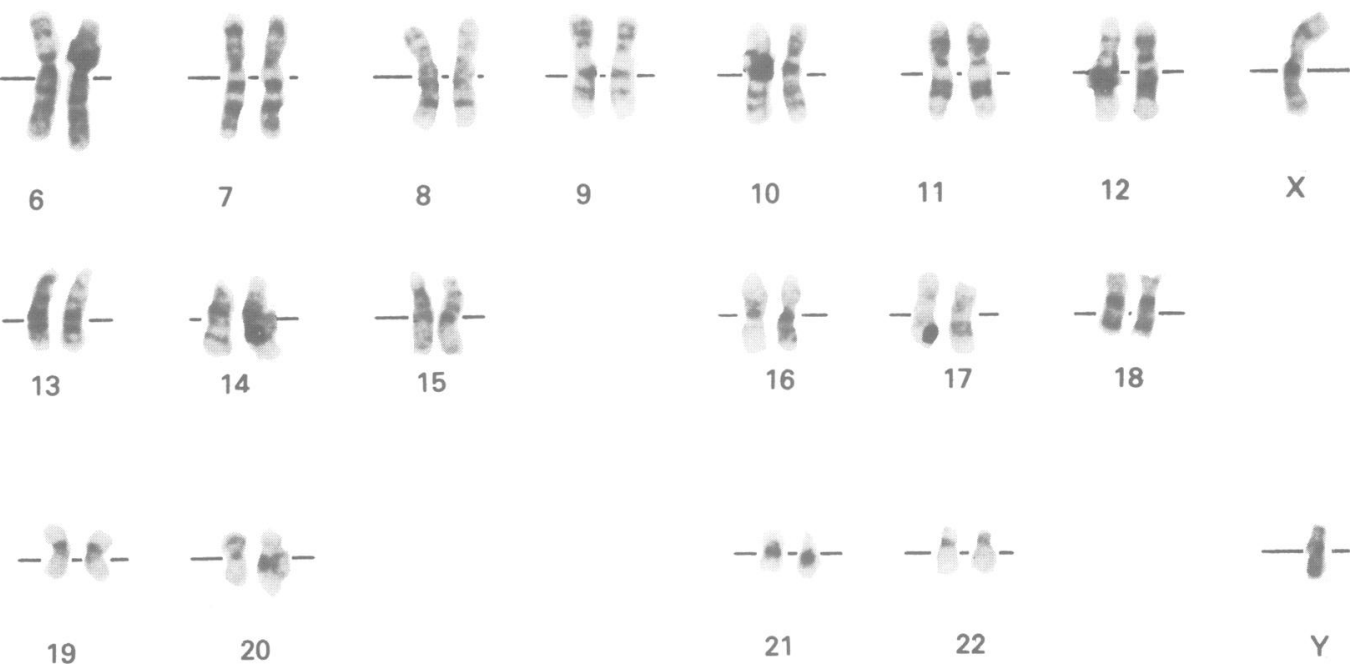

Figure 3 Karotype of case 1. Note large pericentric inversion of right chromosome 1. 
sions and spermatogenic impairment, a more comprehensive characterisation of inversion carriers at the clinical level is necessary. Only if seminal, endocrine, and histological parameters are meticulously documented might patterns of genotype-phenotype correlation emerge.

This work was supported in part by grants from the Deutsch Forschungsgemeinschaft (DFG Me 1086/1-1 and DFG N $130 / 11)$.

1 De Braekeleer M, Dao TN. Cytogenetic studies in male infertility: a review. Hum Reprod 1991;6:245-50.

2 Barros A, Tavares MC, Gomes MP, Tavares MP. Familial inv(1)(p36.3q12) associated with sterility. F Med Genet 1986;23:90-1.

3 Batanian J, Hultén MA. Electron microscopic investigations of synaptonemal complexes in an infertile male carrier of a pericentric inversion inv(1)(p32q42). Hum Genet 1987;76:81-9.
4 Chandley AC, McBeath S, Speed RM, Yorston L, Hargreave TB. Pericentric inversion in human chromosome and the risk for male sterility. $\mathcal{F}$ Med Genet 1987;24:32534

Gabriel-Robez O, Ratomponirina C, Rumpler Y, Le Marec B, Luciani JM, Guichaoua MR. Synapsis and synaptic adjustment in an infertile human male heterozygous for pericentric inversion in chromosome 1. Hum Genet 1986;72:148-52.

6 Guichaoua MR, Delafontaine D, Taurelle R, Taillemite JL, Morazzani MR, Luciani JM. Loop formation and synapic adjustment in a human male heterozygous for two pericentric inversions. Chromosoma 1985;93:313-20.

7 Rivera H, Alvarez-Arratia MC, Moller M, Diaz M, Cantu M. Familial inv(1)(p3500q21.3) associated with azoospermia. Hum Genet 1984;66:165-7.

8 Tóth A, Gaál M, Sára G, Lázlo J. Pericentric inversion of 1982;19:303-5.

9 Bergmann M, Behre HM, Nieschlag E. Serum FSH and testicular morphology in male infertility. Clin Endocrinol 1994;40:133-6.

10 Daniel A, Hook EB, Wulf G. Risks of unbalanced progeny at amniocentesis to carriers of chromosome rearrangements: data from United States and Canadian laboratories. Am $\Im$ Med Genet 1989;31:14-53. 